\title{
Saberes em construção: videogames e motivação na aprendizagem de língua estrangeira
}

\author{
Knowledge under construction: video games and motivation in foreign language \\ learning
}

Resumo: A motivação é listada como uma das variáveis afetivas da qual depende o sucesso na aprendizagem. Segundo Dörnyei (2005), a motivação está relacionada a um dos aspectos mais básicos da mente humana, e boa parte dos professores e pesquisadores concordam que a motivação tem papel importante na determinação de sucesso ou fracasso em qualquer situação de aprendizagem. A palavra motivação tem origem no verbo latino movere, que significa mover, sendo definida, então, como o que leva o indivíduo a fazer escolhas, a se engajar em certas atividades e a persistir nessas ações. $\mathrm{O}$ surgimento dos videogames nos remete aos Estados Unidos da década de 40. Esses jogos revolucionam a indústria de entretenimento e se proliferaram por todo o mundo, chegando aos aparelhos que conhecemos hoje, modernos, com alta tecnologia e mais, mediadores da aprendizagem de línguas. Este estudo tem por objetivo propor uma leitura dos princípios de aprendizagem de James Paul Gee em relação à aprendizagem por meio de videogames a partir das estratégias motivacionais para aprendizagem de língua estrangeira propostas pelo psicólogo Zóltan Dörnyei. Trata-se de uma tentativa de melhor compreender o papel facilitador para a aprendizagem de línguas inerentes aos videogames aliados ao seu potencial motivacional.

Palavras-chave: motivação; videogames; aprendizagem; língua estrangeira

\begin{abstract}
Motivation is listed as one of the affective variables in which success on learning depends on. Dörnyei (2005) reports that motivation is related to one of the most basic aspects of the human mind, and a great deal of teachers and researches agree that motivation plays an important role in the determination of success or failure in any learning situation. The word motivation comes from the Latin verb movere, which means to move, and it is defined as what leads the person to make choices, engage in an activity and persist in these actions. The videogames emerged in the United States in the 40 's. These games revolutionized the entertainment industry and spread out all over the world, coming to the new devices we know today, modern, with high technology, and mediators in the language learning. This study aims at reading the learning principles of James Paul Gee in relation to the learning with videogames, starting from the motivational strategies for language learning proposed by the psychologist Zóltan Dörnyei. It is an attempt to better comprehend the role of language learning facilitator inherent to videogames allied to its motivational potential.
\end{abstract}

Keywords: motivation; videogames; learning; foreign languages

* Aluna do curso de Mestrado em Estudos Linguísticos da Universidade Federal de Uberlândia (UFU). 


\section{Introdução}

A motivação dos alunos é comumente citada como um dos fatores a permear o sucesso na aprendizagem de línguas estrangeiras. Os estudos sobre motivação em aprendizagem de línguas surgiram a partir de trabalhos realizados na Psicologia e foi apenas a partir da década de 70 que começaram a ser, timidamente, associados à Linguística Aplicada.

Desde os primórdios dos estudos sobre motivação, Corder (1967, p. 164) já afirmava que dada a motivação, é inevitável que o indivíduo não aprenda se devidamente exposto à língua alvo. Embora sua afirmação assuma um tom pragmático, há que se ressaltar que ela nos remete ao pressuposto de que a motivação é vista como um componente necessário para que a aprendizagem aconteça. A motivação envolve as atitudes e estados afetivos que influenciam no grau de esforço que os alunos empenham para aprender uma língua estrangeira (ELLIS, 2008, p. 75).

No Brasil, os estudos sobre motivação são recentes, tendo como um de seus marcos iniciais a dissertação de mestrado intitulada: "A Variabilidade da Motivação no Processo de Aprender Língua Estrangeira na Escola”, a qual foi desenvolvida no programa de mestrado em Linguística Aplicada na Universidade de Campinas (UNICAMP). Nesse trabalho, Viana (1990) analisou a variabilidade da motivação no processo de aprendizagem em sala de aula de língua estrangeira. O pesquisador afirma que o termo motivação tem sido usado com base em seu sentido popular, ou seja, como sinônimo de "estímulo (...), impulso, entusiasmo, interesse, vontade, prontidão (p.41)"。

Grande pesquisador da motivação, professor de línguas e formador de professores, o psicólogo Zóltan Dörnyei da Universidade de Notthingan, coleciona inúmeras publicações em temáticas que englobam a psicologia, aquisição e uso de língua e metodologia de ensino de línguas. Dörnyei $(2001,2007)$ reúne em seu livro "Estratégias motivacionais em sala de aula" (Motivational strategies in the language classroom), um panorama geral sobre a motivação, sua conceituação e importância para a aprendizagem de língua estrangeira, colocando em relevo seus reflexos práticos em sala de aula. Como o autor argumenta, comumente usamos o termo motivação para explicar o porquê as pessoas pensam ou se comportam de determinado modo. No entanto, não raro, adota-se o termo de forma muito abstrata e hipotética, baseandose em modelos idealizados e pouco satisfatórios em explicar como esta pode ser efetivamente incentivada em sala de aula. Dörnyei adota uma visão com a qual compartilhamos, de que é uma das funções do professor ser um motivador para os alunos. 
O livro cumpre, então, uma proposta de discutir estratégias motivacionais, ou seja, métodos e técnicas que podem ser utilizadas para gerar e sustentar a motivação dos aprendizes. Outros estudos já haviam se dedicado a definir o que é motivação, seus componentes e dimensões e como esse construto influencia na aprendizagem. A singularidade do livro veio no sentido de demonstrar como o conhecimento teórico sobre motivação é relevante para os professores, e como esses podem ser aplicados em sala de aula.

Conforme evidenciado por diversos estudos (DE HAAN, 2011; VIDAL, 2011) e partindo de nossa experiência como professores de língua, é grande o número de pessoas que dedicam horas e horas a jogar videogames. A indústria de videogames compõe um empreendimento milionário, que movimenta o setor de entretenimento por todo o mundo, agregando um público fiel e diversificado. Hoje, existem incontáveis jogos disponíveis no mercado, os quais esbanjam tecnologia, novidade e interatividade. Embora não fosse seu propósito inicial, há algum tempo o videogame começou a despertar o interesse de linguistas aplicados por parecer cumprir uma nova função. Muito além de um mero passatempo, diversão ou simples entretenimento, o videogame revelou-se, pouco a pouco, um grande colaborar na aprendizagem de línguas. Ele se faz presente nos lares de mais de 60 milhões de brasileiros, o que equivale a dizer que um terço da população tem videogame. Isso é o que indica uma pesquisa divulgada pelo Ibope (Instituto Brasileiro de Opinião Pública e Estatística) em 2012.

O linguista James Paul Gee, atualmente, professor na Universidade do Estado do Arizona, nutre interesse por psicolinguística, letramentos, identidades, ensino de línguas e videogames. Em sua obra "O que o videogame tem a nos ensinar sobre aprendizagem de línguas e letramentos" (What video games have to teach us about learning and literacy), Gee (2007) discute os benefícios que o videogame pode trazer para a educação, e apresenta os 36 princípios que julga adequados para se pensar o videogame como ferramenta potencial de aprendizagem.

Este artigo tem como objetivo ilustrar os princípios elencados por Gee e proceder a uma leitura interpretativa associando-os às estratégias motivacionais na sala de aula sugeridas por Dörnyei. Nesse sentido, buscou-se construir uma discussão teórica ancorada nesses autores, partindo da hipótese de que os princípios de Gee, se analisados à luz das estratégias motivacionais para salas de aulas de línguas propostas por Dörnyei, podem ser relevantes para se pensar no quanto tais princípios além de organizar a aprendizagem mediada por videogame 
pode ajudar na compreensão do poder do videogame na motivação dos alunos e como isso ocorre.

Para tanto, no primeiro tópico, traçamos um breve histórico do caminho percorrido pelos estudos sobre motivação na aprendizagem de línguas. No segundo tópico, discorremos a respeito do potencial dos videogames na aprendizagem de línguas, assuntos esses que direcionam nosso referencial teórico. No tópico de número três, apresentamos nossa análise dos princípios de aprendizagem por intermédio de videogames descritos por Gee à luz de nossa leitura das estratégias motivacionais na sala de aula de línguas estrangeiras pensadas por Dörnyei, desvelando então, nosso objetivo de mostrar como as estratégias de Dörnyei podem ser atreladas aos ideais para uma aprendizagem efetiva por meio de videogames. Por último, trazemos nossas considerações finais, ressaltando o quanto o uso inteligente de videogames pode propiciar a aprendizagem de línguas e ainda surtir efeito motivacional, e dessa forma, contribuir para a aprendizagem de línguas.

\section{Motivação e aprendizagem de línguas}

A motivação é vista como um elemento chave para que o ensino e aprendizagem de uma língua ocorram de maneira eficiente, estando entre os fatores que influenciam o sucesso ou insucesso dos aprendizes. Todavia, falta consenso entre os estudiosos em demonstrar se a motivação é que produz uma aprendizagem com sucesso ou se é a aprendizagem com sucesso o que aumenta a motivação (GÓMEZ, 1999, p. 61).

O interesse no papel da motivação provavelmente se deve ao fato de que essa variável de diferença individual se relaciona de forma decisiva com a transformação de desejos e interesses em ação. Ajuda, pois, na compreensão de como fatores cognitivos e contextuais interagem de modo dinâmico e complexo na constituição da motivação.

Como outrora mencionado, os estudos sobre motivação para a aprendizagem de línguas nasceram a partir de estudos em Psicologia. Não obstante, convém lembrar que a motivação para aprender línguas é diferente de outros tipos de motivação. Isso porque a motivação é constituída por fatores sociais e psicológicos, uma vez que para aprender a língua, espera-se que o aprendiz não adquira simplesmente conhecimento da língua, mas se identifique com a língua alvo, sua cultura e com sua comunidade de falantes e possa adotar características comportamentais de sua fala e estilo. 
Nos primórdios de tais estudos, Gardner e Lambert (1972), em uma abordagem sociocultural da motivação, investigaram a motivação da comunidade falante de francês para aprender inglês no Canadá. Propuseram uma distinção entre motivação integrativa e instrumental. A primeira reflete o interesse pessoal pela comunidade e cultura falante da língua alvo e o desejo de se aproximar de tal grupo. Esse é o caso do desejo de se comunicar com falantes nativos, de assistir filmes, ouvir música, por exemplo. A segunda reflete os valores práticos e vantagens que se pode obter ao aprender aquela língua. Esta é, então, vista como uma ferramenta que nos possibilita alcançar algo, tais como diplomas, empregos, oportunidades.

Já na década de 90, Dörnyei propõe que a motivação deve ser vista sob um eixo temporal composto de três fatores, o nível da língua, o nível do aprendiz e a situação de aprendizagem. No nível da língua, centralizam-se as orientações e motivos relacionados aos vários aspectos da língua, como a cultura e os usos potenciais da proficiência da língua. No nível do aprendiz, o foco reside no aspecto cognitivo e afetivo que perpassa o processo motivacional. No nível da situação de aprendizagem, temos os motivos extrínsecos e intrínsecos para aprender e as condições motivacionais em cada área, tais como componentes específicos de um curso, a prática do professor e a interação com o grupo. Williams e Burden (1997) listam entre os fatores internos que regulam a motivação, o gosto pela língua, a curiosidade, o esforço e as atitudes em relação à língua. Como motivos externos, a presença de outros, tais como os pais, professores e colegas, as recompensas ou punições que determinada atividade pode trazer, o material didático e a escola.

Em 2005, Dörnyei, amparado no trabalho intelectual de Markus e Nurius (1986 apud Dörnyei, 2005), renova os estudos sobre motivação ao propor uma teorização baseada nos "eus-possíveis", na qual a motivação é vista sobre uma perspectiva futura. Divide-se entre o "eu-ideal" que constitui os objetivos e aspirações que o indivíduo gostaria de obter; o "eudever" que se refere às responsabilidades e obrigações que os outros acreditam que eles deveriam assumir e a experiência de aprendizagem que caracteriza os fatores situacionais específicos, relacionados ao ambiente de aprendizagem e suas experiências. A motivação, nessa nova perspectiva, é fomentada a partir de seus estudos da teoria da discrepância de Higgins (1987 apud Dörnyei, 2005), e refere-se às atividades guiadas na tentativa de reduzir a discrepância entre o "eu-ideal" (aquilo que o individuo gostaria de se tornar) e o "eu-real" (o que ele é no momento atual). A motivação pode ser interpretada também como a tentativa de 
reduzir a distância existente entre o "eu-real" e o "eu-dever", ou seja, entre os atributos que o aluno possui no presente e o que os outros acreditam que ele deveria possuir. Embora não conceitualmente caracterizado, nessa teoria temos ainda outro elemento, que é o "eu-temido" que corresponde ao estado que ele não quer vivenciar. Tal sistema é chamado de sistema automotivacional de aprendizagem de segunda língua (L2 Motivational Self System), que formaliza o processo motivacional centrado e desenvolvido pelo indivíduo a partir de uma visão que perpassa os momentos presente e futuro. Esse modelo tem sido implementado nos estudos sobre motivação e hoje se encontra em uma fase de consolidação, sendo muito associado a estudos sobre identidade de professores e alunos. Para exemplificar, imaginemos uma sala de aula, e um aluno que resolveu estudar uma língua, digamos o inglês, porque quer fazer um intercâmbio e morar em Londres, conseguir estudar e se comunicar bem com as pessoas. O seu "eu-real" é de um jovem estudante que desconhece a língua, o "eu ideal" é um jovem que vive e estuda em Londres sem problemas em entender e se fazer entendido. Para isso, existe um "eu-dever" que assegura que para que isso aconteça, ele deveria se matricular em um curso de línguas, estudar, dedicar-se, cercar-se de fontes de contato com a língua. Isso em contraste com seu "eu-temido", que é a imagem de um jovem perdido em Londres que não consegue conversar com as pessoas e nem mesmo acompanhar suas aulas e estudar. Esses são componentes do sistema automotivacional de aprendizagem, o qual transparece como mais focado no aluno e considera a motivação tendo como referência principal o próprio indivíduo.

Nesse sentido, o conceito de motivação integrativa, outrora proposto por Gardner, é revisitado. A integratividade passa a ser incorporada ao "eu-ideal". No mundo globalizado, com o diálogo constante entre línguas que cruzam fronteiras, e na conceituação do inglês como língua mundial, língua franca, a língua mais presente em currículos escolares, e os novos e diversos meios que temos de acessar a língua, muitos deles propiciados pelos avanços com a tecnologia, a mobilidade internacional e migração, a integratividade passa a ter um foco interno, como um processo interno de identificação com seu “eu-ideal”. Há agora um fluido e flexível movimento de pessoas que vai além de determinadas culturas e comunidades físicas ou virtuais. A ideia da motivação para aprender inglês é determinada por um processo de identificação, descrita em termos do senso de uma identidade desejada como cidadãos globais, capazes de transgredir e engajar em várias culturas e comunidade, socialmente ou profissionalmente. Assim, a motivação integrativa passa a ser vista como uma aspiração 
pessoal, como uma imagem futura de si, como, por exemplo, um "eu-ideal", falante fluente em língua inglesa (USHIODA, 2012).

Kubanyiova (2009) defende que essa teoria da discrepância tem como chave a ideia de que as pessoas são movidas com o fim de atingir um estado que corresponda aos estados desejados para o futuro, que são pessoalmente relevantes para eles. A distância entre como eu sou/estou e quem eu gostaria de ser ou como gostaria de estar em certo ponto do futuro é que causa uma dissonância emocional que me motiva a agir para buscar alcançar tal estado.

$\mathrm{Na}$ atualidade, os estudos sobre motivação a percebem como um construto que não pode ser analisado separadamente do contexto em que se situa o processo de aprendizagem. A motivação é temporal, podendo oscilar devido a diversas influências tanto internas como externas. Essa perspectiva dinâmica nos permite considerar como contínuas as múltiplas influências entre o ambiente formal de aprendizagem e fatores singulares ao aprendiz em toda sua componente complexidade, assim como compreender as possíveis alterações tanto no ambiente quanto no aprendiz como resultado de seu desenvolvimento (DÖRNYEI; USHIODA, 2012).

Segundo Kubanyova (op. cit.) faz-se necessário entender como os professores podem atuar e serem preparados para atuar de modo a usar estratégias motivacionais ou adotar uma prática mais motivadora. Teorias e modelos de motivação têm sido persistentes em conceituála. Entretanto, os estudos na área ainda caminham por margens estreitas e pouco luminosas quando o tópico em questão é a motivação e a incorporação de novas tecnologias no ensino de línguas. Como motivar os nativos digitais? Como aliar teoria e prática nos estudos sobre motivação? E, particularmente, por que o uso de videogames tem sido atrativo para a aprendizagem dos alunos? Muito além de classificar a motivação segundo divisões, cumpre investigar como nossas pesquisas podem contribuir para que professores possam diretamente exercer, aquilo que tomamos com uma de suas funções, que é motivar os alunos. Como motivar os alunos do século XXI a aprender e como tais teorias podem ser efetivamente maximizadas e compreendidas em sala de aula é o desafio que se coloca aos educadores da era digital.

\section{Videogames e motivação para a aprendizagem de línguas}

Nossos aprendizes de línguas são personagens que figuram em um novo cenário de aprendizagem. Os avanços tecnológicos apresentaram a alunos e professores outros 
horizontes nunca antes pensados como forma de chegar ao conhecimento a partir de uma variedade de recursos não restritos às paredes da sala de aula. Tais paradigmas, inevitavelmente mudaram a dinâmica do processo de aprendizagem, ao mesmo tempo em que trouxeram a ele vivacidade ao torná-lo mais centrado na pessoa do aluno. Uma das ferramentas a ser considerada são os videogames, que além de sua velha e conhecida função de divertir e entreter, concederam aos alunos um mecanismo novo de ter contato com línguas estrangeiras e criaram uma atmosfera real e autêntica para a aprendizagem de línguas.

O videogame é o dispositivo eletrônico no qual o usuário (jogador) interage através de imagens que são reproduzidas em uma tela de televisão ou monitor (SANCHEZ, 2012). Na Columbia enciclopédia virtual, encontramos a definição de videogame como um jogo eletrônico, dispositivo ou programa de computador que aprovisiona entretenimento através de situações que desafiam o jogador em sua coordenação motora e habilidades mentais. Ainda segundo informações provenientes dessa enciclopédia, muito da atratividade dos videogames é proveniente de um programa de computador que sincroniza luzes e sons em um formato idêntico ao de filmes e exibidos por meio de computação gráfica. Os jogadores podem brincar com outros participantes ou sozinhos, competindo contra a máquina.

Os aprendizes de línguas estrangeiras de hoje são parte de uma geração que cresceu junto às novas tecnologias digitais. Computadores, câmeras, celulares, internet e videogames fazem parte de seu dia-a-dia. Esses alunos constituem a Geração-N (Net Generation) ou Geração-D (Digital Generation). Eles são os nativos digitais, são falantes nativos da linguagem dos computadores, da internet e dos videogames (PRENSKY, 2001).

Os chamados nativos digitais possuem características peculiares. Conforme Prensky (2001), eles estão acostumados a receber informações rapidamente, eles gostam de fazer várias atividades ao mesmo tempo e preferem ler gráficos e desenhos antes de textos. Os nativos digitais preferem o acesso a diversificados meios de informação simultaneamente, como o hipertexto. Eles trabalham melhor quando estão interconectados, buscam gratificações instantâneas e recompensas frequentes e aprendem com facilidade. Eles preferem jogos a trabalho "sério". Por intermédio dessas características, já nos é possível evidenciar como essa geração encontrou no videogame uma fonte de contato com o mundo.

Por outro lado, aqueles que não nasceram na era digital, mas foram por ela atraídos e conseguiram se adaptar harmoniosamente são os chamados imigrantes digitais. De criança a adultos, o videogame exerce atração sobre pessoas de todas as faixas etárias, oferecendo jogos 
baseados em diferentes habilidades, áreas temáticas, estilos e preferências. Os jogos aparecem, então, como ponto a ligar essas gerações.

Tapscott (1998) pontua que para a Geração-N, jogar e aprender podem ocorrer simultaneamente. Um aspecto importante a ser lembrado é que isso está acontecendo por meio de invenção, criação, compartilhamento e uso de jogos digitais para aprendizagem, tanto para crianças como adultos. O que torna os jogos um sucesso na visão de Prensky (op. cit.) é a combinação da motivação do jogo, que te leva a aprender mesmo sem ter consciência disso, somada à metodologia de aprendizagem, que é rápida, efetiva e diferente à da éscola tradicional.

Segundo Tavares (2011), a aprendizagem fundamentada em jogos consiste em toda e qualquer atividade, que se utilize principalmente de jogos, digitais ou não, mas também de outras mídias relacionadas, como meio ou fim para a realização do ensino-aprendizagem, as quais não se limitam ao ambiente e ensino formais.

Mattheiss et al. (2001) afirmam que o sucesso de jogos na aprendizagem advém, dentre outros fatores, do aspecto motivacional para a aprendizagem que os jogos têm, ao levar o indivíduo para a aprendizagem, por vezes, sem que ele perceba. Além disso, por meio de jogos, o aprendiz fica engajado no processo, o que é um elemento crucial para que a aprendizagem ocorra.

A aprendizagem mediada por jogos digitais tem a especificidade de ser ao mesmo tempo divertida e participativa, alem de colocar em conjunto aprendizagem efetiva e entretenimento interativo (PRENSKY, 2001), o que contribui para que seja intrinsicamente motivadora para os aprendizes. O grande marco a ser pensado é que o conteúdo a ser aprendido, informações, conceitos, relações, dentre outros, já não se limita a ser apenas dito aos alunos. É preciso que seja aprendido por eles mesmos, via perguntas, descobertas, construção, interação e acima de tudo, diversão.

Como citado no tópico anterior, a motivação é importante por energizar o processo de aprendizagem. Gee (op. cit) chega a afirmar que quando a motivação acaba, a aprendizagem acaba e o jogo acaba. Ele afirma que bons jogos são motivadores para muitas pessoas, então eles podem nos dar dicas de como a motivação pode ser gerada e mantida. Os aprendizes praticam uma ação à distância e essas ações fazem com que o indivíduo se sinta como se seu corpo e mente estivessem incorporados em um novo espaço, o que gera um estado motivador. Cremos que a sensação que temos é de viver em outro mundo. Ao 
manipular seu personagem e tomar decisões, o aprendiz tem mais ânimo para investir no jogo. Esse investimento parece ser a chave para a motivação e para prosseguir com o desejo de aperfeiçoar no jogo. Os jogos nos auxiliam na compreensão de como as pessoas investem em novas identidades ou papéis, o que podem ser circunstâncias motivadoras para uma aprendizagem nova e profunda. Gee conclui então que a magnitude dos jogos de computador e videogames reside em permitir que as pessoas se recriem a si mesmas em novos mundos e desfrutem de recreação e aprendizagem paralelamente.

$\mathrm{O}$ videogame tem a potencialidade de dar ao jogador a vestidura de uma nova identidade. Squire (2006) enfatiza que nesse contexto, ocorre uma aprendizagem por meio de ser e fazer. Enquanto no passado os jogos educacionais usavam o contexto como atmosfera para a experiência do jogo, os jogos contemporâneos literalmente colocam o jogador dentro do sistema do jogo. Eles têm a habilidade de fazer com que as pessoas fiquem horas sentadas diante deles, mesmo depois de um dia cansativo, atentos e ativamente tentando atingir resultados, vibrando com suas conquistas e determinados a superar deslizes o tempo todo. (PRENSKY, 2003)

Acredita-se que uma sessão de videogame produz um impacto permanente no indivíduo, de modo mais intenso do que um livro, uma música ou um filme, visto que há um envolvimento físico maior do sujeito. (LEFFA et al, 2012) Ainda segundo esses autores:

$\mathrm{O}$ jogador de um videogame age sobre o jogo. O leitor de um livro ou o espectador de um filme processa a informação de modo receptivo, o leitor usando os olhos e o espectador, acrescentando aos olhos os ouvidos, já que não apenas vê, mas também ouve. O videogame vai mais longe: o jogador, além de olhos e ouvidos, usa as mãos e, em alguns jogos, o corpo inteiro; não apenas assiste ao que acontece, vendo a ação do lado de fora da tela, mas interfere no rumo da ação, como se estivesse do lado de dentro. (p. 220)

O videogame reúne no jogador características que nós, enquanto professores, gostaríamos de ver em todos os nossos alunos, são interessados, competitivos, colaborativos, e sempre à procura de informações e soluções. É preciso estarmos alertas para o fato de que os jogos podem sim, ser efetivos na aprendizagem, porém, isso não implica dizer que todos os jogos são bons para todos os aprendizes, e para todas as situações de aprendizagem. A nosso ver, isso apenas aumenta as visões preconceituosas ainda existentes contra a prática social de jogar videogame. 


\section{Os princípios de Gee e as estratégias motivacionais de Dörnyei: em busca de novas leituras}

Em seu clássico livro "O que os videogames têm para nos ensinar sobre aprendizagem e letramento", James Paul Gee (2007), expõe uma análise dos benefícios que o uso de videogames pode trazer para a aprendizagem. "Eu quero falar sobre videogames (...) e dizer coisas positivas sobre eles", nessas palavras, Gee abre seu livro, no qual nos apresenta uma série de 36 princípios de aprendizagem a partir de seus estudos sobre a complexidade e aprendizagem autodirecionada que os aprendizes aderem ao iniciarem um novo jogo. Gee analisa de modo geral as atividades cognitivas, dentre elas, como os indivíduos desénvolvem um senso de identidade, construção de conhecimento, reflexão, como percebem o mundo, como aprendem por meio desses jogos. Ele sugere que alunos, professores e criadores de jogos devem aderir a esses princípios para tornar real a possibilidade de aprendizagem por meio de videogames. A seguir, apresentamos um recorte dos princípios de Gee e sobre eles refletimos à luz das ideias de Dörnyei.

Iniciamos nossa discussão a partir de dois princípios que enaltecem o papel ativo que o aprendiz deve assumir no jogo e/ou na aprendizagem. A começar pelo "Princípio da aprendizagem ativa e crítica" (Active, Critical, Learning Principle), temos a afirmação de Gee de que todos os aspectos do ambiente de aprendizagem, incluindo os modos como o domínio semiótico é elaborado e apresentado, são estabelecidos de modo a encorajar uma aprendizagem ativa e crítica, ou seja, não passiva. Já no "Princípio de pensamento sobre o domínio semiótico" (Metalevel thinking about semiotic domains principle), somos advertidos de que aprender envolve pensamento ativo e crítico sobre as relações entre o domínio semiótico que está sendo aprendido e outros domínios semióticos.

Recorrendo a Dörnyei (2001, p. 77), um meio de tornar a aprendizagem mais estimulante para os alunos é fazer com que eles se sintam parte essencial da aprendizagem, isso pode fazer com que eles gostem da tarefa proposta. Assim, cumpre criar situações nas quais o aprendiz seja chamado a ser participante ativo, nas quais possa opinar, interagir, se posicionar diante de sua aprendizagem. Isso pode ocorrer, por exemplo, quando além de ser participante, o aprendiz tem uma função específica a desempenhar, algo que compete a ele e a mais ninguém. Ademais, em ambientes formais de aprendizagem, tais como a escola, o nível de frequência dos alunos é compulsório e o conteúdo do currículo é quase sempre selecionado pelo professor, pela instituição, ou simplesmente pelo livro didático, muitas vezes, com base 
no que eles e a sociedade consideram importante, e não a visão dos próprios alunos sobre o que julgam importante para si mesmos, o que pode afetar sua motivação para aprender. Ao tratar da motivação, é difícil convencer os alunos a aceitarem os objetivos de determinadas atividades de sala de aula, se não considerarmos se os eles gostam ou não das atividades e se escolheriam se engajar nessas atividades caso tivessem a chance de escolher outras alternativas (DÖRNYEI, 2001, p. 50). Nos jogos, os alunos tem a flexibilidade de montar seus horários, de buscá-los com a frequência que quiserem, muitas vezes sem ter que sair de casa para isso, e escolher o que querem jogar. Isso pode aumentar o senso de autonomia e de motivação, e ajuda a formar alunos mais ativos, participativos e críticos.

Por meio do "Princípio semiótico" (Semiotic principle) e do "Princípio do domínio semiótico" (Semiotic Domains Principle), aprender envolve aperfeiçoar o domínio semiótico e ser capaz de participar, de certo modo, no grupo de afinidade ou grupos ligados a ele. Entendendo domínio semiótico como um complexo de fenômenos culturais e sistemas sígnicos, isto é, sistemas de significação, esse princípio nos lembra que a motivação para aprender pode ser despertada pela integratividade, ou seja, pelo desejo de interagir ou mesmo de fazer parte da cultura local, de interagir com os falantes nativos e de compreender seus signos culturais. Isso reflete uma disposição e identificação em relação a tudo o que é associado à língua, sua cultura, seus falantes, sua influência. Essa integratividade surge quando a língua é vista como "real" pelo falante. Cumpre lembrar que a motivação é socialmente e culturalmente construída. Assim, por meio dos jogos, o aluno pode interagir de perto com a cultura da língua alvo e mesmo jogar com participantes que vivem onde tal língua é falada (DÖRNYEI, 2001, p. 54) .

Não há dúvidas de que língua e cultura são interligados. Aprender uma língua vai muito além de aprender um código de comunicação e suas regras gramaticais, exige incorporar diversos elementos de sua cultura, mesmo que o aprendiz nunca tenha visitado outro país. As pessoas não vivem em um vácuo social, elas são parte de uma cultura, e usam a língua para expressar essa cultura. Ensinar uma língua abrange então, trazer outra cultura para a vida do aprendiz. Para melhor exemplificar a pertinência do aspecto cultural, aludimos outros três princípios, são eles, o "Princípio de modelos culturais sobre o mundo" (Cultural models about the world principle), o "Principio dos modelos culturais sobre a aprendizagem" (Culture models about learning principle), e o "Princípio de modelos culturais sobre o domínio semiótico" (Culture models about semiotic domains principle). Em 
suma, tais princípios advertem que a aprendizagem ocorre de modo que os aprendizes podem pensar conscientemente e reflexivamente sobre seus modelos culturais a respeito do mundo, sobre eles mesmos enquanto aprendizes e sobre um domínio semiótico específico em que estejam aprendendo sem denegrir suas identidades, habilidades ou filiações sociais, e justapõem esses modelos para novos modelos que podem conflitar entre si ou mesmo se interrelacionarem de vários modos. $\mathrm{O}$ aprendiz é levado a pensar sobre sua cultura em relação à cultura do outro e sobre sua cultura de aprender. Ele pode repensar conscientemente sobre novos modelos de aprendizagem e sobre ele mesmo como aprendiz.

Por intermédio do "Princípio da moratória psicossocial" (Psychosocial moratorium principle), temos a indagação de que nos jogos, os aprendizes podem correr riscos em um espaço em que as consequências que teriam no mundo real são reduzidas. Parece ser consenso entre os estudiosos que para propiciar a motivação é necessário criar uma atmosfera agradável e segura em sala de aula. Isso ocorre porque em um ambiente em que os alunos se sentem seguros e dotados do auxílio necessário, a norma de tolerância prevalece e os alunos se sentem confortáveis a se arriscarem, pois sabem que não serão submetidos a possíveis críticas ou constrangimentos públicos caso cometam um erro (DÖRNYEI, 2001, p. 40). Tal atmosfera pode ser facilmente transposta ao domínio dos jogos, os quais podem contribuir no sentido de encorajar os alunos a aceitarem desafios e correrem riscos, e até mesmo no sentido de ajudálos a entender os erros como parte do processo de aprendizagem, e pode ser facilmente transposta ao domínio dos jogos, nos quais os alunos estão mais livres de críticas, correções e comparações passíveis a acontecerem em sala de aula. Reduzem, assim, a ansiedade e o medo de exposição. Esses ambientes podem ainda contribuir em encorajar os alunos a aceitarem desafios e correrem riscos, e até ajudá-los a entender os erros como parte do processo de aprendizagem, como convite a tentarem de novo. Nos jogos é o famoso "tente outra vez" (Try again!).

Aprender é um fenômeno que exige uma combinação de desejo e esforço, ou seja, comprometimento. A partir da interpretação do "Princípio do comprometimento com a aprendizagem” (Commited Learning Principle), evidencia-se que, no videogame, os aprendizes se engajam em participar, com muito esforço e prática, como em uma extensão de suas identidades no mundo real em relação à identidade virtual com a qual eles se sentem comprometidos e o mundo virtual que eles veem como obrigação. Sem suficiente motivação, nem mesmo os alunos mais brilhantes, com habilidades notáveis, tem força para persistir em 
seus estudos. A motivação está diretamente ligada ao esforço na execução de tarefas. Uma das características de um aluno motivado é justamente o esforço no cumprimento de tarefas e a persistência para com as mesmas (DÖRNYEI, 2001, p. 5). Nesse sentido, a motivação energiza o processo de aprendizagem. Do mesmo modo, em ambientes de videogame, o simples ato de se engajar, se esforçar e buscar praticar já dão indícios de motivação. Ainda, um dos meios de motivar os alunos a se empenharem em suas atividades é incentivar e propagar uma visão de esforço não como função tediosa ou mesmo penalização, mas como investimento de modo a obter algo futuro, o que pode ser feito por meio desses jogos.

Tomando como referência e aplicando o princípio acima exposto, evidencia-se que Gee coloca ênfase na questão da identidade real e a virtual que o jogador assume. A temática da identidade também transparece no "Princípio da identidade" (Identity Principle), e no "Princípio de autoconhecimento" (Self-Knowlegde principle). De acordo com o "Princípio da identidade", o ato de aprender envolve assumir e brincar com identidades de modo que o aprendiz possa fazer escolhas reais (ao desenvolver sua identidade virtual) e ter amplas oportunidades de mediar as relações entre novas e velhas identidades. Há uma relação tripartida de identidades, visto que os aprendizes relacionam e refletem sobre as múltiplas identidades que possuem no mundo real, no mundo virtual e uma identidade projetiva, que diz respeito a sua projeção no mundo virtual do jogo.

Consideramos ainda que o comportamento humano tem duas dimensões básicas, a direção e a intensidade. A motivação abarca esses dois aspectos, sendo responsável pela escolha de determinada ação, pelo esforço despendido e pela persistência. Assim, a motivação diz respeito a porque as pessoas decidem fazer algo, o quanto de esforço estão dispostas a empregar e por quanto tempo estarão propensas a sustentar a atividade (DÖRNYEI, 2001, p.7). Ao assumir novas identidades, o aprendiz é colocado diante de situações de escolhas que poderia não vivenciar na vida real. Se pensarmos no sistema de automotivação para aprendizagem de língua estrangeira de Dörnyei, em que a motivação consiste na tentativa de diminuir a discrepância entre o "eu-ideal" e o "eu- real", temos concretizados nos jogos uma possibilidade de assumir e antecipar estados de um "eu-ideal" que desejamos alcançar futuramente no mundo real.

Explorar sua identidade pode viabilizar ao aprendiz maior conhecimento sobre si mesmo. Por meio do "Princípio de autoconhecimento", Gee defende que o mundo virtual é construído de um modo em que os aprendizes aprendem não apenas sobre aquele domínio em 
específico, mas também sobre si mesmos, suas habilidades e potencialidades. Para as teorias motivacionais, por mais que o aluno tenha habilidades notáveis e muita facilidade em aprender, ele não conseguirá explorar isso a longo prazo, caso não esteja motivado. Além disso, pode-se chegar ao conhecimento da língua de diversos modos, fazendo uso de diferentes estratégias e um fator determinante em alcançar sucesso na aprendizagem é permitir que os aprendizes descubram quais são os melhores métodos ou estratégias para si mesmos, em suma, descobrir como eles aprendem melhor (DÖRNYEI, 2001, p. 68). Os jogos permitem que os alunos se aventurem, testem suas hipóteses e explorem suas habilidades e dificuldades de modo mais personalizado. O próprio aprendiz é o centro do jogo. Ele tem a chance de incorporar novas identidades, novos papéis e experiências inusitadas, as quais podem fazer com que reflita sobre seus pontos fortes e fracos. Assim, ele pode aprender mais sobre si mesmo.

Destacamos ainda o "Princípio de realização" (Achievement principle). Nele, Gee revela que para aprendizes de todos os níveis de conhecimento ou habilidade, há recompensas intrínsecas desde o início, personalizadas ao nível de cada aluno, esforço, aumento de proficiência e sinais de realização. Sob uma perspectiva dinâmica da motivação, esta não pode ser vista como um atributo que se mantém estável durante o processo de aprendizagem, porquanto passa por oscilações devido a influências de diversos fatores internos e externos. Dentre os componentes internos temos os autoconceitos, os quais envolvem definições pessoais e julgamentos ou expectativas de sucesso. A expectativa de sucesso, a visão de que ele pode ser alcançado, coloca o indivíduo a caminho de buscar suas metas, o que podemos visualizar claramente nos jogos (DÖRNYEI, 2001, p. 20). Além disso, quando o indivíduo é movido por motivação intrínseca, a atividade em si é gratificante e provê recompensas, fazendo com que o aprendiz se sinta realizado (DÖRNYEI, 2001, p. 57).

Para Dörnyei, nós fazemos as coisas melhor quando esperamos ser bem sucedidos nelas, similarmente, aprendemos melhor quando esperamos sucesso. Um dos meios frutuosos de motivar os alunos é ajudar a aumentar sua expectativa de sucesso, organizando conscientemente meios de colocar o aprendiz com uma visão positiva de suas possibilidades. Além disso, é preciso não colocar os alunos diante de atividades que são muitos difíceis para seu nível de conhecimento, isso também pode colaborar em criar expectativas de sucesso. Percebemos que no videogame, o aluno se sente desafiado a continuar jogando quando percebe que está ganhando. É difícil ser tomado pela tentação de desistir do jogo quando se 
está ganhando e vê que está se superando. Isso reforça o esforço como algo válido. A cada etapa vencida ele tem novo ímpeto em continuar a prosseguir, o que é motivador para os alunos.

Tal princípio nos reporta ainda ao "Princípio do regime de competência" (Regime of competence principle), segundo o qual nos jogos, o aluno tem ampla oportunidade de operar seus recursos, então aqueles mais difíceis, seus obstáculos, são sentidos como desafios, mas não como coisas impossíveis de serem realizadas. De modo semelhante há o "Princípio da aprendizagem contínua" (Ongoing learning principle). Esse princípio defende que a distinção entre o aprendiz e o supervisor é vaga, pois os aprendizes, graças à operação do "regime de competência", devem, em níveis maiores ou menores, desfazer-se de suas rotinas de domínio para se adaptar a situações novas e passíveis de mudança. Existem ciclos de novas aprendizagens, automatização, reorganização de informações. Nos jogos, os alunos se veem como participativos e, a cada instante, podem ser surpreendidos ao longo do trajeto com situações que não haviam sido previamente planejadas, as quais desafiam seu raciocínio e a capacidade de rápida tomada de ação, abrindo espaço para novos conhecimentos, o que cria estímulo para que, a partir de um pequeno insumo, de pequenas informações, eles tenham que problematizar para buscar saídas e, por isso, expandirem seus conhecimentos a partir desse pequeno input inicial. Tal caracterização é retratada no "Princípio de amplificação do insumo" (Amplification of input principle).

Além disso, ao se depararem com situações novas, o elemento de novidade tem a função de eliminar o tédio, o que ocorre quando algo sobre a atividade é diferente ou totalmente inesperado (DÖRNYEI, 2001, p. 76). Aliás, esses princípios são bons exemplos de promoção da motivação intrínseca, a qual tem origem em fatores internos ao aprendiz, dentre esses, temos o interesse intrínseco pela atividade, o qual pode surgir ao despertar a curiosidade do aluno ou pelo quanto a atividade o desafia. Esse desafio deve vir no momento certo e em nível que o desafio a enfrentá-lo e não como algo que ameace suas certezas (DÖRNYEI, 2001, p. 20). Uma das facetas mais motivantes no conteúdo de uma atividade é justamente a chance de desafio. Os seres humanos gostam de serem desafiados, como é evidenciado pela fascinação que temos com palavras cruzadas, quebra-cabeças ou jogos de computador, e o mesmo se aplica a correr riscos, desde que esses sejam moderados. Tal aspecto pode ser referenciado em tarefas nas quais os aprendizes precisam resolver problemas, decifrar enigmas, descobrir algo, superar obstáculos, evitar armadilhas, encontrar 
informações úteis. Esse tipo de atividade é sempre bem-vinda na tentativa de motivar os alunos (DÖRNYEI, 2001, p. 76). Tais concepções podem ser facilmente verificadas nos videogames. A todo momento, o aprendiz se vê desafiado a enfrentar novas situações, pensar em como resolver, decifrar enigmas, escapar de perigos. Os jogos têm esse caráter desafiador que serve de estímulo para os alunos prosseguirem. Entrelaçado a esse pensamento, percebemos que nos jogos, o grau de dificuldade das tarefas é gradual, aumenta à medida que os alunos são capazes de mudar de nível, enquanto não completam as tarefas daquela fase não podem ir para a fase seguinte.

Ao postular o "Princípio de rotas múltiplas" (Multiple routes principle), Gee defende que há múltiplos meios de fazer progresso, de seguir em frente nos jogos. Isso permite que os aprendizes façam escolhas, se apoiem em seus próprios pontos fortes e estilos de aprendizagem e resolução de problemas, enquanto exploram estilos alternativos. Desse modo, aprender é um ciclo de provar o mundo (fazendo algo), refletindo sobre suas ações e, formando suas hipóteses, reprovando o mundo e testando suas hipóteses, e assim, aceitando ou repensando suas hipóteses, o que é expresso pelo "Princípio de teste" (Probing principle). Ambos os princípios têm como foco a autonomia do aprendiz, que pode fazer escolhas, testar quais estratégias de aprendizagem quer adotar e assim, assumir maior responsabilidade. A liberdade para fazer escolhas ao invés de ser forçado ou imposto a se comportar de determinado modo para atender os desejos de outros é um pré-requisito para a motivação (DÖRNYEI, 2001, p. 51). Ao fazer uma avaliação retrospectiva do processo, os aprendizes podem rever suas experiências passadas de aprendizagem, perceber quais os tipos de atividades que funcionaram ou não para eles e assim repensar o que pretendem adotar no futuro (DÖRNYEI, 2001, p. 82). Podemos trazer esses mesmos pressupostos para os videogames, uma vez que permitem que o jogador faça e refaça seu caminho e repense nas melhores estratégias para atingir suas metas, atuando de acordo com suas próprias vontades e centrados em explorar seus pontos fortes.

No videogame, os significados dos signos (palavras, ações, objetos, artefatos, símbolos, textos, etc.) estão situados em experiências incorporadas. Significados não são descontextualizados, é o que diz o "Princípio da aprendizagem situada" (Situated Learning principle), com o qual concatenamos o "Princípio do texto" (Text principle) e o "Princípio da intertextualidade" (Intertextual principle). Para Gee, nos jogos, os textos não podem ser entendidos apenas verbalmente, porém, em termos de experiências incorporadas, de modo que 
os aprendizes possam se mover continuamente entre textos e experiências incorporadas e, assim, extrair sentido entre o jogo e o mundo. Há uma conexão entre o mundo real e o virtual que se torna motivante. Um dos fatores mais desmotivantes para o aprendiz é quando este tem que aprender algo em que ele não vê razão para aprender porque não lhe parece ser relevante a qualquer aspecto de sua vida. A fim de tornar os textos e outros recursos didáticos motivadores, esses precisam estar ligados a temáticas, de algum modo relacionadas a assuntos de experiência do dia-dia e pertinentes as suas realidades pessoais (DÖRNYEI, 2001, p. 64). A ideia é simples: os alunos não estarão motivados a aprender a menos que eles considerem que o material a ser aprendido é relevante para eles. Para tanto, é necessário conhecer os interesses, gostos, objetivos e necessidades dos alunos, só assim poderemos relacionar o conteúdo curricular a seus interesses e experiências. Com os videogames, até mesmo a seleção de temas é baseada na temática geral do jogo a que o aprendiz se propõe, permitindo que escolha assuntos que lhe interessem. A aprendizagem é gradativa, processual, contextualizada e adequada ao nível de conhecido esperado para o aprendiz. Isso pressupõe que os elementos são conexos e relevantes para os aprendizes. $\mathrm{O}$ aspecto motivacional consiste em estabelecer uma ligação entre os tópicos e atividades de sala de aula com experiências reais e preferências dos alunos (DÖRNYEI, 2001, p. 66). Nesse aspecto, o uso do videogame é vantajoso. Finalizando a discussão acerca desta temática, reportamo-nos ao "Princípio do subconjunto" (Subset principle), o qual descreve mais detalhadamente a ideia de que aprender, desde o início, deve ocorrer em um subconjunto do domínio real.

Através do "Princípio multimodal" (Multimodal principle), do "Princípio da inteligência material" (Material intelligence principle) e do "Princípio do Design" (Design principle), inferimos que nos jogos, significado e conhecimento são construídos por meio de várias modalidades (imagens, textos, símbolos, interações, formatos abstratos, som, etc.). Acrescente-se a isso que pensar, resolver problemas e constituir conhecimento são focalizados em ferramentas, tecnologias, objetos materiais e no ambiente. Isso liberta os alunos para engajarem suas mentes em outras coisas ao mesmo tempo em que combinam os resultados de seu próprio pensamento com o conhecimento armazenado nessas ferramentas, tecnologias, objetos materiais, e no ambiente para atingir aprendizagem afetiva. Isso pode permitir um perfil mais autônomo, democrático e cooperativo nos alunos que permite que explorem melhor o mundo a sua volta a seu modo (DÖRNYEI, 2001, p. 106). No quesito motivação, além de enriquecer a aprendizagem, essa diversidade de recursos quebra a monotonia. Às 
vezes, é bom fazer o inesperado e variar aspectos do ensino e dos recursos usados. Uma ocasional fuga da rotina pode trazer um novo fluxo motivacional (DÖRNYEI, 2001, p. 74). Buscando uma comparação corriqueira, nosso apetite começa a ser despertado quando olhamos para o prato, para sua aparência, mas também pelo conteúdo, pelo sabor, pela textura, pelo que sentimos quando o experimentamos, isso cria o desejo de querer comer. Como professores, o segredo não é mudar todos os ingredientes todas as vezes que fazemos uma receita, mas tomar cuidado para não servir todos os dias a mesma refeição. Nos jogos, essa conjuntura desperta o desejo de jogar e aprender de modo dinâmico e em constante renovação.

Passemos então a discutir a questão conhecimento teórico e prático nos jogos. Em concordância com o "Princípio prático" (Practicle principle), os aprendizes têm muita prática em um contexto em que a prática não é tediosa (no mundo virtual) e, por isso, passam horas dedicados à tarefa. Destarte, o "Princípio do conhecimento intuitivo" (Intuitive knowlegde principle) reitera que o conhecimento intuitivo ou tácito construído por meio de prática e experiência é igualmente importante e reconhecido. O conceito de motivador é bem próximo ao conceito de interessante. As pessoas estarão dispostas a passar o tempo pensando e aprendendo enquanto fazem atividades que lhes interessem. Por isso, a aprendizagem não pode assumir a faceta de algo chato e tedioso. Se conseguirmos fazer com que o processo de aprendizagem se torne mais estimulante e agradável estaremos contribuindo grandemente para manter o envolvimento e a motivação dos alunos (DÖRNYEI, 2001, p. 72). Podemos inferir que se os alunos empregam horas nos videogames, tais atividades chamam sua atenção, são práticas e roubam o tédio, o que facilita a motivação. Além disso, como Dörnyei (2001, p. 05), ressalta, durante o longo e, frequentemente, tedioso processo de aprendizagem de uma língua estrangeira, o entusiasmo, comprometimento e persistência do aluno são determinantes de sucesso ou fracasso. A estratégia sugerida é usar a fantasia para animar a tarefa. Essa estratégia pode ter várias formas, seja pelo jogo ou pela criação de cenários imaginários, tratando objetos ou personagens de outros modos (DÖRNYEI, 2001, p. 113).

Em síntese, o "Princípio incremental" (Incremental principle), o "Princípio de amostra concentrada" (Concentrated sample principle) e o "Principio das habilidades básicas" (Bottom-up basic skills principle), nos mostram que a aprendizagem ocorre em etapas e deve começar de um nível de complexidade mais simples e aumentar gradualmente, acompanhando também o preparo dos alunos em executar as tarefas propostas. A nosso ver, 
Gee vem nos dizer que nos estágios iniciais, situações de aprendizagem são requeridas para preparar os aprendizes para os casos posteriores. O aprendiz se depara, nos níveis iniciais, com instâncias de sinais e ações fundamentais que formam um modelo mais controlado, para aos poucos, adquirirem prática; executando-as com frequência até chegar a tarefas mais livres para sua liberdade de expressão. As habilidades a serem desenvolvidas permitem que o aprendiz adentre cada vez mais no domínio do jogo, sem isolar-se do mundo em que vive.

Aqui retomamos a noção de que o sucesso não depende exatamente de quão difícil é a tarefa, mas de quão preparados os alunos estão para executá-la. Pré-atividades, demonstrações e exemplos são também úteis no sentido de provê-los de informação e experiência. Pensar nos possíveis obstáculos que podem interferir no atingimento de suas metas também ajuda os alunos a se preparem de modo a prevenir-se ou a como enfrentá-los. Além disso, pensando na relação motivação e sucesso, não é segredo que o sucesso alimenta o sucesso, e dosagens de sucesso aumentam a motivação. Se os alunos percebem que tem um bom desempenho em situações iniciais se sentem impulsionados a continuar (DÖRNYEI, 2001, p. 89). Nos jogos, quando o aprendiz muda de um nível para outro, aumentando o grau de dificuldade, ele se torna mais preparado para tarefas mais complexas, o que nos lembra uma sequência didática propriamente dita. Se essas situações tem relação com sua vida pessoal, as habilidades que estão praticando poderão ser úteis em prepará-los para enfrentar situações similares na vida real.

Abordando em conjunto o "Princípio da informação explícita sob-demanda e no momento certo" (Explixit information on-demand and just-in-time principle), o "Princípio da descoberta" (Discovery principle) e o "Princípio da transferência" (Transfer principle), somos advertidos de que no videogame, ao mesmo tempo em que informações são disponibilizadas ao aprendiz no momento em que ele as procura, seja no momento em que precisa ou antes do jogo. Há também oportunidades para experimentar livremente e fazer descobertas, as quais podem ser transpostas para o mundo real. Constitui estratégia motivacional uma atmosfera que ofereça suporte ao aluno, seja por meio do material, da figura do professor ou de colegas, ou no caso dos jogos, pela tecla “Ajuda". Também é considerado motivador que os alunos saibam qual o propósito e a utilidade das tarefas, isso os ajuda a canalizar esforços e aderir a esse propósito, assim podem ver a tarefa não como imposição, mas como oportunidade para aprender e descobrir coisas novas, que possam ser aplicadas em situações necessárias da vida real (DORNYEI, 2001, p.80). Assim, deve existir 
um balanço entre informações explícitas e chances de descobertas, de modo a conciliar o que o deixa seguro e o lhe desperta a curiosidade. Afinal, quando você lê o resumo de um filme, e o assiste na sequência, se já sabe todos os detalhes do que vai acontecer, perde o frio na barriga.

Passemos ao "Princípio da distribuição" (Distributed principle) e ao "Princípio da dispersão" (Dispersed principle), os quais ao aliar significado e conhecimento, afirmam que estes são distribuídos entre o aprendiz, o os objetos, as ferramentas, símbolos, tecnologias e o ambiente que o circunda e, do mesmo modo, partilhados com outros, fora do domínio do jogo, mesmo com algumas pessoas que ele raramente encontrará face-a-face. Dentre as condições necessárias para gerar a motivação, existe a criação de um grupo de aprendizagem coeso, o qual se constitui de língua alvo, professor, alunos e recursos disponíveis. Um grupo de aprendizagem coeso se propõe a fazer as atividades juntos e existe um forte senso de "nós", um sentimento coletivo, no qual os alunos estão contentes em fazer parte dele. A coesão, nesse sentido, refere-se ao comprometimento de cada membro do grupo com a língua alvo e uns para com os outros, é o "magnetismo" que mantém o grupo unido. Nos jogos, essa coesão, pode ser manifestada, por exemplo, em procurar interação e partilha com os membros do jogo, dentro ou fora de seu domínio. A motivação dos alunos tende a aumentar em grupos de aprendizagem coesos (DORNYEI, 2001, p.43). Isso se deve ao fato de que em tais grupos os alunos dividem uma responsabilidade em comum em atingir as metas do grupo, eles podem incentivar uns aos outros, e a relação positiva entre eles torna o processo de aprendizagem mais prazeroso em geral.

Tendo discutido os princípios de distribuição e dispersão, os relacionamos ao "Princípio do grupo de afinidade" (Affinity group principle). Nele Gee argumenta que os aprendizes constituem um "grupo de afinidade", isto é, um grupo que é unido, primeiramente, através de esforços conjuntos, metas e práticas. Um meio de motivar um grupo é encorajar a cooperação entre seus membros. Eles podem se sentir mais seguros para enfrentar desafios em saber que não estão sozinhos e que a responsabilidade é partilhada, assim, os riscos e ameaças parecem ser reduzidas. Outra estratégia motivacional é que o grupo tenha um objetivo em comum, pois, quando trabalham na direção desse objetivo a tendência é que a expectativa de sucesso que nutrem seja maior. Além disso, quando existem esforços conjuntos em busca de algo, um pode se sentir na missão de motivar o outro em momentos de dificuldade. Esse trabalho em grupo pode despertar o senso de que sua contribuição é única, que seu papel é 
importante e a satisfação que eles experimentam é aumentada pela partilha e comemoração em conjunto (DORNYEI, 2001, p.100), o que pode ser evidenciado no videogame, em jogos de grupo.

Por fim, reportamo-nos ao "Princípio do participante” (Insider principle). O aprendiz é um "participante", "professor" e "produtor", e não somente um "consumidor", capaz de personalizar a experiência de aprendizagem e o domínio do jogo desde o início e ao longo de toda a experiência. Quando é permitido ao aprendiz ser protagonista, ele tem mais chances de ter suas expectativas pessoais atingidas, o que aumenta sua motivação. Destarte, a aprendizagem é mais personalizada focando seus interesses e seus objetivos pessoais. As pessoas tendem a ser naturalmente motivadas quando sentem que são participantes ativas em algo. Acrescente-se a isso que estabelecer metas é uma estratégia motiyacional que pode ajudar o aprendiz a estruturar e planejar seu processo de aprendizagem. Essas metas devem ser claras e específicas, descrevendo resultados possíveis, e não baseadas em crenças irrealistas, mas sim, plausíveis e desafiantes. As metas também são eficazes como meio para que os alunos avaliem sua própria performance e progresso e analisem pontos falhos no caso do não atingimento dessas metas e, assim, possam avaliar se o esforço empregado foi suficiente e se as estratégias usadas eram as mais apropriadas (DÖRNYEI, 2001, p.121). Ao satisfazer a esse princípio, os jogos são também motivadores.

\section{Considerações finais}

Neste artigo, trouxemos reflexões acerca do construto motivação e sua influência no sucesso na aprendizagem de língua estrangeira. Em seguida, discorremos acerca do videogame e elencamos que seu uso é uma constante para os aprendizes na atualidade e encontra resguardo na sua eficácia em mediar o processo de aprendizagem de línguas. Expomos nossa visão de que parece ser senso comum afirmar que o videogame é motivador, no entanto, urge que estudos específicos sobre a motivação e o uso de videogames, sejam desenvolvidos de modo a buscar cientificidade em tal relação, em ter maior clareza em entender porque eles são motivadores e, ainda, para se aproveitar melhor seu potencial motivacional na trajetória de aprendizagem de línguas. Ao aliar os princípios de Gee às estratégias motivacionais de Dörnyei, o presente estudo parte da aspiração de contribuir nesse sentido. 
Supomos que nenhum decreto afirme que aprender e jogar devem ser processos autoexcludentes ou mesmo que aprender deva ser uma atividade árdua e maçante que se isente de diversão. Apesar de fazerem uma comparação aos jogos em geral, nos próprios Parâmetros Curriculares Nacionais (PCN), pode-se ler que em um ensino significativo as tarefas correspondem, de preferência, a atividades de comportamentos do mundo extraclasse, podendo representar uma simulação, na sala de aula, de situações vivenciadas em jogos, por exemplo. A esse respeito, é pertinente tomar-se o ponto de vista de Leffa et. al. (2012), ao afirmar que o videogame, visto como um objeto de lazer, pode resultar na aprendizagem da língua, oferecendo ao aluno três opções: (1) aprender a língua para jogar; (2) jogar para aprender a língua; e (3) fazer as duas coisas ao mesmo tempo. Contudo, alertamos que nem todos os jogos são eficazes em propiciar a aprendizagem. Motivo pelo qual apontamos para os princípios de Gee como norteamentos substanciais para guiar a criação e a implementação de videogames e, sobretudo, a seleção de jogos. Como pudemos expor, acreditamos que adotar os princípios postulados por Gee, orienta e traz confiabilidade à relação videogames e aprendizagem. Ao mesmo tempo, são princípios que nutrem características condizentes com enfoques motivadores, conforme o proposto por Dörnyei, podendo, pois, despertar e sustentar a motivação dos aprendizes e, desse modo, viabilizar a aprendizagem. Isso nos permite explorar a hipótese de que os videogames propiciam a aprendizagem, dentre outros fatores, porque são motivadores, logo, dispõem o indivíduo a aprender.

Se os princípios que Gee propõe para o uso de videogames possuem interfaces com as estratégias motivacionais de Dörnyei, ponderamos então, o seguinte questionamento: "Por que não usar videogames em sala de aula"? Cumpre esclarecer que não temos a pretensão de afirmar que é dever do professor instaurar o uso de videogame em sala de aula. Isso porque cremos que motivação e imposição, formam uma rima sem sonoridade. Igualmente, falar em motivação demanda respeitar estilos individuais, desejos, identificação pessoal e estratégias de ensino/aprendizagem. Além disso, sendo um construto socialmente construído e partilhado, a motivação esbarra em limitações contextuais. Contudo, julgamos que é dever do professor motivar os alunos. Na contemporaneidade, enquanto professores e pesquisadores, deparamo-nos com um novo perfil de alunos. Se esses alunos aprendem de modo diferenciado, também são motivados de outras maneiras, o que deve nos instigar, então, a colocar em nossas pautas de discussão, como motivar os nativos digitais. A nosso ver, os videogames se mostram como uma rota possível. 
Caso o professor se sinta convidado a usar efetivamente o videogame em sala de aula, cumpre explorar como se daria esse processo de implementação e a formação de professores e alunos para atuarem nesses ambientes. Tal implementação, passaria por processo semelhante ao de normalização histórica, descrito por Bax e Chambers (2006), até que fossem de fato invisibilizados, e sua presença se tornasse algo tão comum quanto lápis e caderno em sala de aula, o que não é um processo rápido e banal. No entanto, o videogame pode ser empregado como recurso adicional, extraclasse, como meio não só de motivar o aluno, mas de criar oportunidade para que o "aprender" ocorra dentro e fora de sala de aula, rompendo fronteiras. O primeiro passo é contrapormo-nos aos resquícios de uma imagem preconceituosa que ainda circunda os videogames, como se eles fossem inimigos que competem com as horas de estudo dos alunos e, portanto, atrapalham a aprendizagem. Como professores, lançar um novo olhar sobre os videogames, é um meio de conhecer melhor a atmosfera de aprendizagem de nossos alunos.

Em tempos de aprendizagem autônoma e centrada no aprendiz, como declara Dörnyei (2001, p. 50), motivar o aluno envolve, dentre outros fatores, possibilitar condições ou situações de modo que a pessoa possa escolher o curso das ações, trilhar seu caminho. Cremos que nesse movimento em direção a uma prática de ensino mais motivadora para os nativos digitais, mais atenção pode ser dada a investigar os videogames. Por fim, como afirmam Scheidecker e Freemam (1999), motivar os alunos ontem, hoje e amanhã nunca será uma prática singular e um processo simplista.

\section{Referências}

BRASIL. Ministério da Educação e do Desporto. Secretaria de Educação Fundamental. Parâmetros Curriculares Nacionais: Língua Estrangeira - 5a. - 8a. séries. Brasília: MEC/SEF, 1998.

CHAMBERS, A.; BAX, S. Making CALL work: towards normalisation. System, v.34, n. 4, p. 465-479, 2006.

CORDER, S. P. The significance of learner's errors. International Review of Applied Linguistics, v. 5, p. 2-3, 1967.

De HAAN, J. W. Teaching and learning English through digital game projects. Digital Culture \& Education, v. 3, n. 1, p. 03-29, abr., 2011. Disponível em: < http:/ 
/www.digitalcultureandeducation.com/cms/wpcontent/uploads/2011/04/dce1046_deHaan_20 11.pdf $>$. Acesso em: 10 out. 2012.

DÖRNYEI, Z. Motivational strategies in the language classroom. Cambridge: Cambridge University Press, 2001.

. The psychology of the language learning: individual differences in second language acquisition. London, 2005.

DÖRNYEI, Z.; USHIODA, E. Motivation. In: GASS, S.; MACKEY, A. (eds.). The Routledge handbook of second language acquisition. New York: Routledge, p. 396-409, 2012.

ELLIS, R. The study of Second Language Acquisition (2 ed.). Øxford: Oxford University Press, 2008.

GARDNER, R.C.; LAMBERT, E. Attitudes and motivation in Second Language Learning, Rowley, MA: Newbury House, 1972.

GEE, J. P. What video games have to teach us about learning and literacy. Macmillan: New York, 2007, p. 221-229.

GÓMEZ, P.C. A motivação no processo ensino/aprendizagem de idiomas: um enfoque desvinculado dos postulados de Gardner e Lambert. Trabalhos em Linguística Aplicada, v. 34, 1999, p. 53-77.

KUBANYIOVA, M. Possible selves in language teacher development. In: DÖRNYEI, Z; USHIODA, E. (orgs). Motivation, language identity and the L2 self. Bristol, Buffalo, Toronto: Multilingual Matters, 2009, p. 314-332.

LEFFA, V. J.; BOHN, H. I.; DAMASCENO, V. D.; MARZARI, G. Q. Quando jogar é aprender: o videogame na sala de aula. Revista de Estudos Linguísticos, v. 20, n. 1, p. 209230, jan./jun. 2012

MATTHEISS, E.; KICKMEIER-RUST, M.; STEINER, C.; ALBERT, D. Motivation in Game-Based Learning: It's More than 'Flow'. In: SCHWILL, APOSTOLOPOULOS, N (Eds.). Learning in the digital age, p. 74-88, 2009.

PRENKSY, M. Digital natives, digital immigrants. On the Horizon, 9, 5, p.1-6, 2001.

. Digital natives, digital immigrants, part II. Do they really think differently? On the Horizon, 9, 6, p. 1-6, 2001 b. 
. The digital game-based learning revolution. McGraw-Hill, p. 1-20, 2001.

October 2003

Digital Game-Based Learning. ACM computers in entertainment, Vol. 1, No. 1,

TAPSCOTT, D. Growing up digital: The Rise of the Net. McGraw-Hill Companies, 1998.

SANCHEZ, D. B. Videogame - história do videogame, básico 1. Espaço Guarulhos, 2012. Disponível em: http://www.espacoguarulhos.com.br/apostilas/historiadosvideogames/historiadosvideogames. pdf. Acesso em: 02 out. 2012.

SCHEIDECKER, D.; FREEMAN, W. Bringing out the best in students: How legendary teachers motivate kids. Thousand Oaks, CA: Corwin Press, 1999.

SQUIRE, K. From Content to Context: Videogames as Designed Experience. Educational Researcher, Vol. 35, No. 8, p. 19-29, 2006.

TAVARES, R. Inteligência e videogames: o corpo que lê. X SBGames Full Papers, Salvador, p. 1-7, 2011

USHIODA, E. Motivation and L2 learning: Towards a holistic analysis. In: Views on motivation and autonomy in ELT: Selected papers from the XXXVII FAAPI Conference, p. 14-19, 2012.

VIANA, N. Variabilidade da motivação no processo de aprender língua estrangeira na sala de aula. 1990. Dissertação (Mestrado em Linguística Aplicada) - Instituto de Estudos da Linguagem, Universidade Estadual de Campinas, Campinas, 1990.

VIDAL, C. D. Multimodalidade e traduções funcionais para investigar a aquisição de segunda língua em gamers. 2011. Tese (Doutorado) - Programa de Pós-Graduação em Estudos da Tradução, Universidade Federal de Santa Catarina, Florianópolis, 2011.

WILLIAMS, M; BURDEN, Robert. Psychology for language teachers: a social constructivist approach. Cambridge, 1997.

Artigo recebido em: 16.10 .2012

Artigo aprovado em: 18.12.2012 